\title{
A Journey into the Metacognitive Learning Strategies
}

\author{
https://doi.org/10.3991/ijoe.v15i14.11379 \\ Eleni Mitsea ${ }^{(凶)}$, Athanasios Drigas \\ N.C.S.R. 'Demokritos', Athens, Greece \\ e.mitsealgmail.com
}

\begin{abstract}
In the last few decades, there has been growing research interest in investigating the positive relationship between metacognitive strategies, conscious learning, and achievement. However, the lack of a uniform classification indicates a need to map the different approaches, so as to discover the cornerstone strategies that result in ascending the knowledge and consequently the consciousness pyramid. The outcome of this study place executive functions, self-monitoring, and adaptation at the heart of these strategies.
\end{abstract}

Keywords-Metacognitive learning strategies, self-regulation, executive functions, self-awareness, consciousness

\section{Introduction}

The term metacognition could be defined as the ability of individuals to know their cognitive functions, monitor them while they operate, control and adjust them according to the needs of the learning process [1], [2]. Modern studies divide metacognition into two major and interrelated components: metacognitive knowledge and metacognitive regulation [3], [4]. The metacognitive knowledge's sub-components consist of declarative knowledge (knowledge about the way we learn), procedural (knowledge about the appropriate learning strategies) and conditional (knowledge about the context in which strategies could be implemented) [5]. Metacognitive regulation includes planning, monitoring, and evaluation and could be considered as "self-management" of cognition involving reflective "self-appraisal" which supports awareness and has been labeled executive control [6].

Metacognitive strategies refer to conscious monitoring [7], sequential processes to control learning [8], higher order executive skills [9], decisions learners make before, during and after the learning [10]. It has been proved that the implementation of metacognitive strategies empowers higher-order cognitive abilities, attentional and memory control, self-confidence and leads to independent and meaningful learning [11]. Classification of strategies varies, depending on the definitions adopted and the different associations and connotations within different research domains. Despite significant research efforts on metacognition and its learning strategies, there are still confusion and fundamental questions about their precise structure, their functions in gaining self-knowledge in learning and their conjunction with the notion of consciousness. 


\section{Methodology}

The main focus of the present review article was concentrated on the cartography of various metacognitive learning strategies adopted in research studies that revealed a positive relationship between the aforementioned strategies and effective learning. Moreover, repeated strategies with a positive effect on various learning tasks were an equally important criterion. In the present study, we adopt a holistic thinking approach about metacognition, metacognitive strategies, and consciousness. It is hypothesized that all these notions give the distorted impression of complexity or multiplicity, whereas they co-exist in the same spectrum and overlap in a perfect and endless loop, a "henosis" sharing the same substance.

\section{$3 \quad$ Seeking for Metacognitive Learning Strategies}

Nemouchi [12] highlighted a set of interrelated metacognitive strategies for EFL writing in teaching and learning processes. The researcher selected and analyzed strategies with social, affective and cognitive dimensions:

- Planning: Advanced organization: Preview the main ideas, identify the organizing principle. Organizational planning: Plan how to achieve in setting goals, determine the parts and sequence ideas to express. Selective attention: Read and listen selectively focusing on keywords, phrases, ideas, linguistic markers, types of information, scan and isolate the specific information. Self-management: Determine conditions such as the time, the way and the place facilitating your learning.

- Monitoring comprehension and production: Reflect on your own learning style. Gain awareness about your best learning. Define the conditions that ascertain, foster learning. Be concentrated and determine the opportunities for applying the content to be learned in various tasks.

- Evaluating: Reflect on the efficiency of the learning strategies used. Recognize the strengths and the weaknesses.

- The knowledge monitoring skill: Determine what is known and unknown. Direct the attention and resources adequately.

- Cooperative learning: Engage in the learning process. Discuss, analyze, explain and evaluate cooperatively.

- Self-reflection (Self-management): Organize information into a coherent knowledge structure. Analyze situations, generate hypotheses, and decide how to solve problems.

- Metacognitive scaffolding: Relate the use of a given tool to the accomplishment of the task.

- Modeling: Use models of metacognition. Identify and conceptualize the principles in problem-solving.

- Self-questioning: Pose self-questions identifying the mission of important points.

- Thinking aloud and Self-explanations: Externalize the thought processes and the content of a task. 
The aforementioned strategies enable students to accomplish complex tasks, to be independent, self-sufficient and creative self-directed learners. Nemouchi concluded that improved metacognitive strategies comprise a gift that helps students not only to improve their performance but also to raise self-awareness in other words consciousness.

$\mathrm{Du}$ Toit et al. [13] investigated the extent to which metacognitive strategies are used by mathematics learners and teachers in the learning of mathematics. The questionnaire data was based on twelve from the following thirteen metacognitive strategies:

- Planning strategy

- Generating questions

- Choosing consciously

- Setting and pursuing goals

- Evaluating the way of thinking and acting

- Identifying the difficulty

- Paraphrasing, elaborating and reflecting ideas

- Clarifying terminology

- Problem-solving activities

- Thinking aloud

- Journal-keeping

- Cooperative learning

- Modeling

The results of the study revealed that learners employed evaluating the ways of thinking and acting, planning strategies, choosing consciously and identifying the difficulty most. In contrast, cooperative learning, thinking aloud and journal keeping was used to the least extent. In an attempt to explain the different performance, Du Toit concluded that learners appeared to be well-organized and aware of their strengths and weaknesses, notwithstanding it is necessary to be encouraged to verbally express their thoughts in a group setting.

Parlan et al. [14] made an experimental study on the quality of prospective chemistry teachers' scientific explanations. After dividing 62 students of chemistry education program into two classes, the first group was taught by expository learning and the experimental class by metacognitive strategies. The strategies involved in the training sessions were:

- Preparing: Review the teaching ability. Determine the learning goal, choose the learning strategy and arrange the learning schedule. Finally, identify the significant goals, the relevant prior knowledge and the concepts that have been understood and finally make question lists.

- Doing: Get involved in the learning activity.

- Checking: Monitor the planning, assess the learning, check the effectiveness of the learning method, reflect on the learning process used.

- Assessing and following-up: Give the feedback and follow up with the learning outcome. 
The results of data analysis showed that metacognitive learning strategies not only improve the students' ability to construct scientific explanations but also enable students to learn critically and meaningfully.

Segedy et al. [15] presented an integrated cognitive and metacognitive model for effective and self-regulated learning strategies in Betty's Brain, a computer-based open-ended learning environment. The main aim of the aforementioned model was to develop an intervention tool helping learners adopt more effective strategies for preparing and regulating their future learning. Betty's Brain environment is based on the learning-by teaching paradigm. Specifically, middle school students were given the task of teaching a computer agent with the help of a mentor agent so as to gain familiarity with and employ several cognitive and metacognitive skills. Within the area of metacognition, the model illustrates the following metacognitive strategies:

- Goal-setting \& planning: Identify, choose and plan to achieve goals.

- Knowledge of construction: Knowledge acquisition, verification.

- Monitoring: Assess understanding, identify and correct misconceptions and incomplete representations and assess progress toward the goal.

- Help-seeking: Identify impasse or difficulty. Ask a mentor for specific advice or a hint.

The application of this model raises learners' in difficulty awareness since they are motivated to develop more effective learning strategies, seek feedback through a conversation with the mentor agent, and take control of their learning.

Nosratinia et al. [16] examined the relationship of metacognitive learning strategies to listening comprehension achievement on English as a Foreign Language. To fulfill this objective, sixty female and male students were chosen as the participants of the study and were divided into four homogeneous groups: two control groups and two experimental. The last group received Metacognitive Strategy training based on Anderson's 2002 model [17]. According to the aforementioned model, metacognitive strategies consist of five major components:

- Preparing and planning for learning: Set and achieve goals.

- Selecting and using learning strategies in a given context for a specific purpose: Think and make conscious decisions about the learning process.

- Monitoring strategy use: Direct learning progress, revisit the strategies that are employed and ensure the correct implementation of the strategy.

- Orchestrating various strategies: Coordinate, organize, relate different strategies.

- Evaluating strategy use and learning: Make self-questions, debrief discussions after strategy practice.

Intensive statistical analysis on listening post-test revealed a significant difference in scores between the experimental group $(\mathrm{M}=23.43, \mathrm{SD}=1.54)$ and the control group $(\mathrm{M}=19.95, \mathrm{SD}=2.54)$. The magnitude of the difference in the means was so large that Nosratinia concluded metacognitive learning strategies have a significant effect on EFL learner's listening comprehension. 
Ersozlu et al. [18] made quantitative research on the relevance between reasoning skills and their levels of using metacognitive learning strategies. Mathematical Reasoning Rating Scale and Metacognitive Learning Strategies Scale were applied to the first-year students from the Education Faculty. The last scale embodied the following metacognitive subscales: planning strategies, organizational strategies, controlling strategies and assessment strategies.

The findings revealed a positive but weak relationship between reasoning and using planning. A positive and average relationship with organizational controlling and assessment strategies was found. Ersozlu concluded that the candidate teachers may use metacognitive learning strategies at higher-level as their levels of mathematical reasoning increase enabling thinking about mathematical concepts and creating logical links between mathematical relationships.

Kim et al. [19] explored the effects of metacognitive strategies on academic and gaming achievement via player's social problem-solving. To achieve this goal, a Massively Multiple Online Role-Playing Game (MMORPG), Gersang was used as a game-based learning environment in economics, providing scaffolding for problemsolving and fostering intrinsic motivation. After being tested, a homogenized group of 132 ninth grades with the same gaming ability was taught 20 economic concepts by metacognitive learning strategies. In this study, based on three dimensions of metacognition (self-planning, self-monitoring, self-evaluation), three metacognitive strategies were developed:

- Self-recorded strategy: Students were engaged in a three-phase reflective metacognitive process: Firstly, recording their prior knowledge before students start gameplay. Secondly, determining and monitoring if the activities were related to the game mission. Thirdly, recording reflections, upon finishing their gameplay.

- Modeling: The ability of making strategies by observing the others. Modeling requires identification of the game missions and activities, determination of the target player to observe during the play, observation of targets player's strategies and conceptualization of player's own strategies, application of player's own strategies and finally evaluation of their efficacy compared to the target player.

- Thinking aloud: Verbal expression of the covert mental processes. Students use glossaries intended to relate their learning plan to their learning objectives before they start playing and explaining their game process to their fellow players throughout the gameplay.

Participants played the online game 45 minutes a day, twice a week for 10 weeks. Every 20 game-based learning sessions, students completed three checklists for the metacognitive strategies. In the last session, the social problem-solving and the academic achievement post-tests were also completed. Path analysis revealed that metacognitive strategies seem to play an important role in social problem-solving abilities which is the path for academic and gaming achievements. Moreover, 'thinking aloud' strategy is characterized as the best way of creating problem solving abilities.

Shannon [20] investigated the most preferred metacognitive strategies for selfdirected learning. A total of 40 chemistry students were surveyed in the research project using the Perceptual Modality Preference Survey (PMPS) as a learning strategy 
assessment tool. According to the Institute for Learning Styles Research, there are seven percept styles: print, aural, visual, interactive, haptic, kinesthetic and olfactory. Afterward, the students were taught a different metacognitive strategy every week during the 10 weeks project. Eventually, the students reflected on the effectiveness of each strategy with the overall focus of becoming more self-directed learners. The model adopted [21] consists of the following strategies:

- Predicting outcomes: Understand the kinds of information that lead to successful problem solving.

- Evaluating work: Determine the strengths and weaknesses of the work.

- Self-assessing: Reflect on the effectiveness of learning.

- Self-questioning: Use questions to check knowledge during the learning task.

- Questioning by the teacher: Answer teacher's questions during the task.

- Selective strategies: Decide which strategies are useful for a given task.

- Using directed or selective thinking: Choose consciously a specific line of thinking.

- Using discourse: Discuss ideas with each other.

- Critiquing: Provide feedback to other students about their work in a constructive way.

- Revising: Return work after receiving feedback.

Shannon concluded on the strong connection between learning styles and metacognitive strategies. Particularly, the findings indicated that haptic and kinesthetic learners chose to select strategies, while interactive learners preferred critiquing and revising. Furthermore, visual learners used self-questioning and predicting outcomes, aural learners questioning and print learners self-assessing strategies. The majority of the students preferred metacognitive questioning. Among these results, students that used metacognitive questions became more curious and motivated. Finally, throughout the study, the researcher found that no matter the learning style a student might prefer, all of the students continuously evaluate their performance and their progress.

Kisac et al. [22] explored the correlation between the metacognitive strategies and the levels of self-confidence about learning. Managing Metacognition Inventory was applied to 400 university students chosen from different schools and departments. The study focused on three essential skills (planning, monitoring and evaluation) and the following metacognitive strategies:

- Note-taking: Record the main ideas before making decisions about what to write.

- Summarizing: Write brief statements that represent the main ideas.

- Outlining main points of the material in a hierarchical format.

- Reflecting: Relate the prior knowledge with the existing information.

- Reciting: State points out loud, asking and answering questions.

- Reviewing: Ask self-questions, repeat learning.

The results showed that strategies as note-taking, summarizing, outlining and reflecting were used most, while reciting and reviewing means were averages indicating 
that students prefer less recalling and repeating. It was also found that the use of metacognitive strategies coincide with higher levels of self-confidence.

Bautista [23] discerned the learning impact of cognitive and metacognitive learning strategies when used in desktop teaching. A Descriptive-Correlation Research Design was used on twenty-eight first-semester students-respondents of the study. As regards the determination of cognitive and metacognitive strategies, a questionnaire developed by Pintrich et al. [24] was adopted encompassing the following strategies:

- Rehearsal strategies: Activate information in working memory via enumeration, recitation, memorization of keywords and context clues and listing. These strategies influence attention and encoding processes.

- Elaboration strategies: Store information into long-term memory by building internal connections between items to be learned. Paraphrase, summarize, create analogies and take notes so as to associate new information with prior knowledge.

- Organization strategies: Select the appropriate information and construct connections among to information to be learned. Examples of organizing strategies are clustering, outlining and selecting the main idea.

- Critical thinking: The application of previous knowledge to new situations in problem-solving, decision making and in critical evaluation.

- Self-regulation strategies: Activities that lead to control of cognition and awareness through three general processes: planning (goal setting, task analysis), monitoring (self-testing, questioning) and regulating (checking and correcting learning behaviors).

The research showed that the student-respondents not only use a variety of cognitive and metacognitive learning strategies but also are aware of the interdependence between successful learning and metacognitive strategy use.

Penuela [25] conducted a qualitative action research study on the impact of using metacognitive strategies on the language awareness of stress and intonation in the context of English as a foreign language. Ten adult learners with difficulties in using suprasegmentals participated in a three-cycle research process which included: training in three metacognitive strategies, identifying suprasegmental features from video or audio input and monitoring of the feature through the metacognitive strategy they had learned respectively. In the current study, three metacognitive strategies were selected regarding mostly Oxford's model [26].

- Overviewing: Center learning. Understand why an activity is being done. Consciously pay closer attention. Relate previous theoretical knowledge to the upcoming tasks.

- Setting goals and objectives: Arrange and plan learning, set aims for language learning and keep track of these objectives in a journal along with deadlines.

- Self-evaluating: Assess progress in the target language by recording and listening to yourself in different controlled and spontaneous tasks.

After analyzing the learning logs, the recorded artifacts and the field notes, Penuela affirmed that language awareness was fostered because metacognitive strategies gave 
them steps towards self-regulation. Specifically, they seemed to be aware of the difficulties and the possible ways to improve. Listening to themselves, students had a more realistic perception of themselves as intelligible speakers and felt more confident despite the difficulties. Penuela suggested a triadic metacognitive-based process for gaining awareness that involves:

- Language awareness

- Self-awareness

- Learning awareness processes.

Tang [27] made comparative research among high and low language achievers of English with the intention to elaborate an effective metacognitive strategy training model based on the identification of their strengths and weaknesses. For this purpose, 166 Chinese students (61 and 105 high and low language achievers respectively) completed the Modified Strategy Inventory for Language Learning of Oxford [26] that consists of the following metacognitive strategies:

- Centering your learning: Overview, pay attention and delay speech.

- Arranging and planning: Organize, set goals, identify, plan and seek practice.

- Evaluating: Monitor and assess yourself.

In respect of the overall strategy use, this study showed that metacognitive strategies are used more frequently and more effectively by high achievers, while the most significant difference was found in evaluating. One of the issues that emerged from these findings is that metacognitive strategies encompass a powerful tool that should be used to support the low achievers becoming consciously aware of their learning processes and progress.

Bazi [28] determined the metacognitive learning strategies of physician candidates and analyzed them in terms of the variables of gender, class level and academic success. The Metacognitive Learning Strategies Scale was applied to 614 male and female $1^{\text {st }}, 2^{\text {nd }}$ and $3^{\text {rd- }}$ year students examining the following metacognitive strategies:

- Organization strategies: Prepare the mind while starting to study. Determine the information according to the existing metacognitive schemas. Define the subjects and the key concepts. Review the context to be learned.

- Planning strategies: Do things in time. Be mentally prepared, be adapted in task's conditions.

- Observation strategies: Focus on the continual self-learning during the learning activity. Compare new with the previous information assessing the accuracy. Determine validity and hierarchical structure of information during learning enabling self-observation.

- Evaluation strategies: Self-assess what is learned and to what extent it is learned. Use strategies including self-testing in terms of information and analyze unknown information according to test results.

Following the collected data, students in general use organization and observation strategies more effectively than evaluation and planning, while female students 
achieve better performance than male candidates. Furthermore, $1^{\text {st }}$-year students surpass the $2^{\text {nd }}$ and $3^{\text {rd }}$-year students, while in literature is argued the opposite thesis. Future research could focus on the relationship between the aforementioned variables and the metacognitive learning strategy use. Metacognitive learning strategies, as a whole, were related to academic success and positive self-perception.

Heidari et al. [29] made an experimental study to evaluate the effect of cognitive and metacognitive strategies learning on academic achievement among nursing students. The study population consisted of 40 nursing students divided into two subgroups of control and experimental. The last group received 10 session training on cognitive and metacognitive learning strategies. At the end of the training, a pre-test, a post-test and follow-up academic achievement test were completed. After the sixth session, the students were taught the metacognitive strategies (strategies for monitoring, guiding, and changing the cognitive strategies if necessary) as follow:

- Planning: Determine the objective of the study. Predict the required time for the study. Identify the speed of study and select a particular cognitive strategy.

- Control and Monitoring: Assess the study progress. Monitor attention and learning. Pose self-questions during the study, control study time and speed, predict examination questions.

- Regulation: Adjust study speed and study time. Modify or alter the cognitive strategy for study.

The current study found that the instruction of metacognitive learning strategies improved significantly the academic achievement. The Anova showed that the mean value of the experimental group was higher than the control group on both tests. For instance, at the post-test, the mean values were 16.67 for the experimental group and 13.47 for the control group.

Mohammadi et al. [30] examined the relationship between metacognitive learning strategies, goal orientation, and test-anxiety in terms of some variables such as gender, age and faculty. A sample of 335 male and female university students filled out a questionnaire which consisted of items on goal orientation, test anxiety and metacognitive learning strategies. The metacognitive strategies consist of:

- Planning strategies: Set goals for learning and studying. Predict the time required to study. Define the appropriate speed of studying. Analyze the way of dealing with the learning subject, select useful learning strategies.

- Monitoring and control strategies: Supervise the learning progress, monitor the attention when reading, ask questions when studying.

- Regulation strategies and regulatory activities: Be flexible, change the learning strategy if necessary. Recognize and resolve ineffective cognitive strategies.

From the data, it is apparent that while there is a significant positive relationship between metacognitive learning strategies and goal orientation, there is, at the same time, a significant negative relationship between the aforementioned dimensions and test anxiety. These results indicate that metacognitive learning strategies and goal orientation comprise contributory factors to the reduction of test anxiety. Another 
important finding was that female students were more anxious. However, the results showed no significant difference between goal orientation means scores in terms of sex. Finally, no significant difference was found between the mean values of goal orientation and test anxiety in terms of faculty and student age.

Partanen et al. [31] examined the significance of using metacognitive strategy training in the rise of working memory's training optimization in children with special educational needs. After selecting and dividing forty primary school children with lower performance in auditory WM, arithmetic, reading and writing skills into two groups, the control and experimental. Both groups were applied a computer-based working memory training program including visuospatial and auditory memory tasks, forward and backward WM processing and various distractors. The experimental group received an additional metacognitive strategy training as follows:

- Labeling: Label the central objects and elements in the tasks so as to establish a common language and facilitate effective cognitive processing of information.

- Goal formation: Formulate the goal of the specific WM training task, to identify the strategy.

- Cognitive strategies: Identify and formulate strategies for both success and failure on the task.

- Planning and metacognitive strategies: Share and summarize important planning and strategies to self-monitor during training.

- Transfer: Reflect on the relation between the tasks in the WM training and situations outside training context, to facilitate transfer to areas of school learning or leisure time.

The results obtained from the analysis revealed a significant difference in working memory performance, especially to the visuospatial tasks, during training in favor of the metacognitive intervention. However, no increase in cognitive abilities or to the school-related skills associated with the intervention was found. More research needs to be undertaken in designing educational interventions based on metacognitive strategies and working memory training.

Adedipe et al. [32] made a descriptive survey focused on the awareness of basically English as Second Language students in comprehending their academic materials though the application of metacognitive strategies. For that reason, 120 secondary students filled in a metacognitive reading strategies questionnaire. The descriptive analysis which examines the extent to which students are aware of metacognitive strategies include the following items:

- Skimming

- Scanning

- Questioning

- Inference

- Verifying

- Prediction

- Monitoring

- Summarizing 


\section{- Visualizing}

The questionnaire that analyses the extent to which students apply metacognitive strategies in reading and comprehension concentrates on:

- Seeking help while reading about the words' meaning

- Adjustment of the reading rate to the reading material

- Paraphrasing text information while reading

- Getting the meaning instantly

- Remembering what have been read.

Data showed that over $60 \%$ of the students were aware of various metacognitive strategies and apply these strategies in a reasonable extent. Adedipe concluded that students need more metacognitive strategy training to perform better in examinations and to be more efficient.

Thompson et al. [33] examined the influence of a combined intervention including neurofeedback and metacognitive learning strategies training on students with Attention Deficit Disorder. For this purpose, 111 participants of whom 98 children and 13 adults attended forty 50-min sessions twice a week receiving neurofeedback, so as to control attributes of brain wave activity. When the feedback indicated that the participant was focused, metacognitive strategies were taught. The kinds of strategies taught included:

- Word analysis skills for decoding

- Active reading strategies

- Listening skills

- Organizational skills for making a presentation, writing a paragraph or writing an essay

- Answering exam questions

- Tricks for times tables

- Solving word problems in math

- Organizing study time

- Creating mnemonic devices

- Preparing study notes

The above-mentioned techniques emphasized on remaining alert while listening or studying and organizing and synthesizing material to aid recall. Although the study was not controlled, the results associate the aforementioned intervention with general students' improvement in areas of intellectual and academic functioning. Furthermore, symptoms associated with ADD, for instance inattention, distractibility, impulsivity were regulated making an impact in listening and reading abilities. It is worth noting that adults enhanced their organizational time-management skills and their memory, while some students ameliorated their self-esteem. The students performed better on IQ tests and they were more reflective and verbally forthcoming. Thompson argued that metacognitive strategies combined with neurofeedback could function better than other interventions for ADD. 
Ku et al. [34] investigated the effective use of metacognitive strategies to critical thinking performance. For this purpose, 10 university students with different critical thinking performances participated in 6 thinking tasks using think-aloud procedures so as to verbalize their thoughts. A metacognitive coding scheme was developed intergrading low and high-level metacognitive strategies into groups according to the following dimensions:

- Planning: Identify procedures and requirements of a task. Be aware of the need for planning (low-level strategies). Specify planning actions (high-level strategies).

- Monitoring: Check the understanding/lack of understanding (low level). Discriminate important or ambiguous information (high level).

- Evaluating: Make a conscious examination of task's improvement (low-level). Revise the thoughts (high-level).

A positive correlation was found between good critical thinkers and high-level metacognitive strategy use. Specifically, high performers were efficient at planning for specific steps, in thinking and revising their task approach after determining problems.

Yang et al. [35] made an in-depth study of metacognitive strategy use to six Chinese $\mathrm{Ph} . \mathrm{D}$. students of social sciences in Australian universities. The main process consisted of three stages of interviews the last of which focused on the use of metacognitive strategies. Participants mentioned a variety of metacognitive strategies which were divided into the following categories:

- Planning: Advance planning, goal setting, establishing priorities.

- Self-monitoring: Checking the effectiveness and/or efficiency of one's learning, self-reflecting.

- Self-evaluating: Identifying strengths and weaknesses, judging consciously the quality of one's self as a researcher.

The analysis revealed that $\mathrm{Ph} . \mathrm{D}$. candidates made use of all the major categories of metacognitive strategies and were able to better manage their studies. Yang concluded on the critical role of metacognitive strategy use in the timely completion of doctoral theses as well as in self-confidence and sophistication.

Pei-Lan-Lei et al. [36] investigated the effect of the students' metacognitive strategies and verbal-imagery cognitive style on their video research behavior, search and learning performance. For this purpose, 100 Taiwanese fifth graders were asked to search for videos related to natural science teaching materials using video search engines. Students' effectiveness was evaluated according to Brown's perspectives [3] on metacognitive strategies as follows:

- Planning a search and understand the search tasks: Understand the video content first by using the information on the search engine interface. Save time by selecting videos with detailed descriptions and more explicit metadata information. Reduce keywords in the search process.

- Monitoring progress: Enter keywords. Search for videos with summaries and understand the video content before watching it. 
- Evaluating the search results: Compare and select relevant videos. Be cautious in assessing the keywords before searching for videos, to avoid changing in searching strategies.

The results revealed that metacognitive strategies comprise the primary influencer of users' video research behaviors and performances. Specifically, students with better planning and evaluating strategies were more conscious about the processes and achieved higher learning performance. It can thus be suggested that the implementation of the metacognitive learning strategies in web information retrieval processes could help students become autonomous learners.

Ghaith et al. [37] researched the interplay of metacognitive strategies and higherorder reading comprehension. In the present study, 119 tenth grade learners of English as a foreign language were examined by the Survey of Reading Strategies (SORS) that included the following metacognitive strategies:

- Global reading strategies: Prepare the reading act by selecting what to read or ignore, noticing text characteristics, guessing what the material is about.

- Problem-solving strategies: Repair strategies used in comprehension problems that involve re-reading. Return to a previous section when losing concentration, taking a pause and thinking about reading, reading aloud, visualizing information.

- Support reading strategies: Support responses to reading by underlining or circling information, paraphrasing for more understanding, going back and forth in the text, note-taking and annotating.

The statistical analysis of the data revealed that the problem-solving strategies not only surpass in frequency the other abovementioned strategies but also function as a predictor of both literal and higher-order comprehension. Ghaith recommended using the problem-solving metacognitive strategies as a mechanism for developing intellectual knowledge and making conscious efforts to monitor and control their reading outcomes.

Panahandeh et al. [38] investigated the effect of metacognitive strategies on argumentative writing accuracy. For this purpose, sixty EFL learners were divided into two groups, a control and an experimental group. The last-mentioned group received metacognitive strategy training based on O'Malley and Chamot's model [39] focusing on planning and monitoring:

- Planning: Advance organizing, directed attention, self-management, functional planning.

- Monitoring: Monitoring of comprehension and production, auditory, visual, styling, plan and double-checking monitoring.

- Evaluating: Evaluation of production, performance, ability, strategy, and language.

The present study revealed that the experimental group not only was aware of metacognitive learning strategies and utilize the strategies consciously but also surpassed the control group in writing achievement. In general, therefore, it seems that meta- 
cognitive strategies could be characterized as a predictor of English written proficiency.

\section{Conclusion}

The scope of the current review study was to map the major metacognitive strategies involved in learning and their learning impact through a journey into some representative research studies. Unsurprisingly, the findings showed that metacognitive strategies enhance learners' academic achievement, self-confidence and raise selfawareness. Moreover, it was revealed a significant co-occurrence of the metacognitive strategies and high-level cognitive functions such as reasoning, critical thinking and problem-solving. As far as the classification of strategies concerned, despite some different approaches, most researchers look upon the metacognitive strategies as selfmonitoring's, adaptation's and self-regulation's (or executive functions') builders. The results of this study support the idea that metacognitive strategies bind cognitive and metacognitive abilities together into a comprehensive simultaneous whole, increasing visibility of the true self of knowledge in a unified universe. Imagine metacognition like a tunnel (such as tunnel of time) and metacognitive strategies like the vehicle which could unveil countless and possible paths with the same destination: the stream of consciousness. This stream of luminosity becomes gradually visible as people make a journey in new, alternative or more trodden paths and climb the ladder of knowledge, bridging information gaps in a meaningful whole. The stages of consciousness we could experience coincide with the evolution of the counterpart metacognitive strategy levels. The above-mentioned point of view was inspired also from Drigas' [40], [41] eight-layer model of "Consciousness-Intelligence-Knowledge" and nine-layer model of giftedness. Future research could forge a universal metacognitive strategy model in accordance with the aforementioned knowledge-consciousness models.

\section{$5 \quad$ References}

[1] J. H. Flavell, "Metacognition and cognitive monitoring: A new area of cognitive- developmental inquiry," American psychologist, vol. 34, no.10, p. 906, 1979. https://doi.org/ 10.1037//0003-066x.34.10.906

[2] S. G. Paris \& P. Winograd, "How metacognition can promote academic learning and instruction," Dimensions of thinking and cognitive instruction, vol. 1, pp. 15-51, 1990.

[3] A. Brown, "Metacognition, executive control, self-regulation, and other more mysterious mechanisms" In F. E. Weinert \& R. H. Kluwe, (Eds.) Metacognition, motivation, and understanding, pp. 65-116, Hillsdale, NJ: Lawrence Erlbaum, 1987.

[4] G. Schraw and R.S. Dennison, "Assessing metacognitive awareness," Contemporary educational psychology, vol.19, no. 4, pp. 460-475, 1994. https://doi.org/10.1006/ceps.1994. $\underline{1033}$

[5] G. Schraw and D. Moshman, D., "Metacognitive theories", Educational psychology review, vol. 7, no.4, pp. 351-371, 1995. https://doi.org/10.1007/bf02212307

[6] P. Tarricone, "The taxonomy of metacognition," Psychology Press, 2011. 
[7] J. Flavell, "Monitoring social cognitive enterprises: Something else that may develop in the area of social cognition," in Social cognitive development: Frontiers and possible futures, J. Flavell and L. Ross, Eds. New York: Cambridge University Press, 1981, pp. 272287.

[8] J. Livingston, "Metacognition: An overview, " unpublished manuscript, State University of Buffalo, 2003.

[9] A. Cohen,Strategies in learning and using a second language. Routledge, 2014.

[10] M. Boekaerts and P Simons, Leren en instructive, Uitgeverij Van Gorcum, 1995.

[11] W. Christine, "Metacognition: Metacognitive skills and strategies in young readers" Unpublished Master of Arts Research Project, Kean University, New Jersey, 2003.

[12] O. Nemouchi, "Metacognitive Strategies for EFL Writing," Revue Sciences Humaines, vol. 48, pp. 159-174, 2017.

[13] A. Du Toit and G. Kotze, "Metacognitive strategies in the teaching and learning of mathematics," Pythagoras, vol. 2009, no.70, pp. 57-67, 2009. https://doi.org/10.4102/pytha goras.v0i70.39

[14] P. Parlan, P. Ibnu, S. Rahayu, and S. Suharti, "Effects of the Metacognitive Learning Strategy on the Quality of Prospective Chemistry Teacher's Scientific Explanations," International Journal of Instruction, vol.11, no. 4, pp. 673-688, 2018 https://doi.org/10.12973/ iiji.2018.11442a

[15] J. Segedy, J. Kinnebrew, and B. Gautam, "Modeling Learner's Cognitive and Metacognitive Strategies in an Open- Ended Learning Environment," In AAAI Fall Symposium Series, 2011.

[16] M. Nosratinia, S. Ghavidel, and A Zaker, "Teaching Metacognitive Strategies through Anderson's Model: Does It Affect EFL Learners' Listening Comprehension?" Theory and Practice in Language Studies, vol. 5, no.6, pp. 1233-1243, 2015. https://doi.org/10.17507/ tpls.0506.16

[17] N. Anderson, "The role of metacognition in second language teaching and learning," ERIC Digest, EDO. Washington, DC: ERIC Clearinghouse on Languages and Linguistics, 2002.

[18] Z. Ersozlu and H. Çoban, "The Relationship Between Candidate Teachers' Mathematical Reasoning Skills and Their Levels of Using Metacognitive Learning Strategies," Mustafa Kemal University Journal of Social Sciences Institute, vol. 9, no.19, pp. 205-221, 2012.

[19] B. Kim, H. Park, and Y. Baek, "Not just fun, but serious strategies: Using meta-cognitive strategies in game-based learning," Computers \& Education, vol. 52, no.4, pp. 800-810, 2009. https://doi.org/10.1016/j.compedu.2008.12.004

[20] S. V. Shannon, "Using metacognitive strategies and learning styles to create self-directed learners, ” Institute for Learning Styles Journal, vol.1, no.1, pp.14-28, 2008

[21] L. Darling-Hammond,K. Austin, M. Cheung, and D. Martin, D, “ Thinking about thinking: Metacognition, Retrieved January 16th, 2008. Available: <http://www.learner.org/ resources/series172.html> 2008.

[22] I. Kisac and Y. Budak, "Metacognitive Strategies of the University Students with Respect to their Perceived Self-confidence Levels about Learning," Procedia-Social and Behavioral Sciences, vol. 116, pp. 3336-3339, 2014. https://doi.org/10.1016/j.sbspro.2014.01.759

[23] R. G. Bautista, "The impact of cognitive and metacognitive learning strategies in desktop teaching," ANGLISTICUM, Journal of the Association-Institute for English Language and American Studies, vol. 1, no. 2, pp. 135-143, 2015.

[24] P. Pintrich and E. De Groot, "Motivational and self-regulated learning components of classroom academic performance," Journal of educational psychology, vol.82, no. 1, 1990 https://doi.org/10.1037//0022-0663.82.1.33 
[25] D. Peñuela, "Using Metacognitive Strategies to Raise Awareness of Stress and Intonation in EFL," Colombian Applied Linguistics Journal, vol. 20, no. 1, pp. 91-104, 2018. https:// doi.org/10.14483/22487085.12383

[26] R. Oxford,"Language learning strategies. What every teacher should know." Boston MA:Heinle \& Heinle Publishers, 1990.

[27] L. Tang, "A Comparative Study of Metacognitive Strategy Use between Language High Achievers and Low Achievers of English in College," International Journal of English Linguistics, vol. 5, no. 5, p. 147, 2015. https://doi.org/10.5539/ijel.v5n5p147

[28] H. Bazı, "An Analysis of Metacognitive Learning Strategies of Physician Candidates in Terms of Some Variables," Cilt, vol. 7, no. 1, pp. 40-46, 2017.

[29] N. Heidari, S. Haghighat, M. Haji, F. Ghorbani, and J. Ashoori, "Impact of Teaching Cognitive and Metacognitive Learning Strategies on Academic Achievement among Nursing Students," Journal of Research Development in Nursing and Midwifery, vol. 13, no. 1, pp. 19-24, 2016. https://doi.org/10.18869/acadpub.jgbfnm.13.1.19

[30] Y. Mohammadi, S. Kazemi, H. Tahan, and S. Lalozaee, "Relationship between metacognitive learning strategies, goal orientation, and test anxiety among students at Birjand university of medical sciences," Journal of Medical Education, vol.16, no. 1, pp. 44-50, 2017.

[31] P. Partanen, B. Jansson, J. Lisspers, and Ö. Sundin, "Metacognitive strategy training adds to the effects of working memory training in children with special educational needs," International Journal of Psychological Studies, vol. 7, no. 3, pp. 130-140, 2015. https://doi.org/10.5539/ijps.v7n3p130

[32] T.H. Adedipe and G. O. Ofodu, "Assessing ESL students' awareness and application of metacognitive strategies in comprehending academic materials" Journal of Emerging Trends in Educational Research and Policy Studies, vol.2, no. 5, pp. 343-346, 2011.

[33] L. Thompson and M. Thompson, "Neurofeedback combined with training in metacognitive strategies: effectiveness in students with ADD," Applied psychophysiology and biofeedback, vol. 23, no. 4, pp. 243-263, 1998. https://doi.org/10.1023/a:1022213731956

[34] K. Ku and I. T. Ho, "Metacognitive strategies that enhance critical thinking," Metacognition and Learning, vol.5, pp. 251-267, 2014. https://doi.org/10.1007/s11409-010-9060-6

[35] C. Yang and L. Bai, "The use of metacognitive strategies by Chinese PhD students of social sciences in Australian universities," International Journal of Educational Research, vol. 97, pp. 43-52, 2019. https://doi.org/10.1016/j.ijer.2019.06.007

[36] P. L. Lei, C. T. Sun, S. S. Lin, and T. K. Huang, "Effect of metacognitive strategies and verbal-imagery cognitive style on biology-based video search and learning performance," Computers \& Education, vol. 87, pp. 326-339, 2015. https://doi.org/10.1016/j.compedu. 2015.07.004

[37] G. Ghaith and H. El-Sanyoura, "Reading comprehension: The mediating role of metacognitive strategies," Reading in a Foreign Language, vol.31, no. 1, pp. 19-43, 2019.

[38] E. Panahandeh and S. Asl, "The effect of planning and monitoring as metacognitive strategies on Iranian EFL learners' argumentative writing accuracy," Procedia - Social and Behavioral Sciences, vol. 98, pp. 1409-1416, 2014. https://doi.org/10.1016/j.sbspro.2014.03. $\underline{559}$

[39] J.M. O'Malley and A.U. Chamot. Learning strategies in second language acquisition. Cambridge: Cambridge University Press, 1990.

[40] A. Drigas and M. Pappas, "The Consciousness-Intelligence-Knowledge Pyramid: An 8x8 Layer Model," International Journal of Recent Contributions from Engineering, Science \& IT (iJES), vol. 5, no.3, pp 14-25, 2017. https://doi.org/10.3991/ijes.v5i3.7680 
[41] A. Drigas, M. Karyotaki and C. Skianis, "Success: A 9 Layered-based Model of Giftedness," International Journal of Recent Contributions from Engineering, Science \& IT (iJES), vol. 5, no.4, pp. 4-18, 2017. https://doi.org/10.3991/ijes.v5i4.7725

\section{Authors}

E. Mitsea (MA in Linguistics) is with Net Media Lab-Mind \& Brain R\&D, Institute of Informatics and Telecommunications, N.C.S.R. 'Demokritos'. Athens, Greece (e-mail: e.mitsea@gmail.com).

A. Drigas is a Research Director at Net Media Lab-Mind \& Brain R\&D, Institute of Informatics and Telecommunications, N.C.S.R. 'Demokritos'. Athens, Greece (email: dr@iit.demokritos.gr).

Article submitted 2019-07-26. Resubmitted 2019-08-29. Final acceptance 2019-08-11. Final version published as submitted by the authors. 